\title{
Development and validation of a portable gas phase standard generation and calibration system for volatile organic compounds
}

\author{
P. Veres ${ }^{1,2}$, J. B. Gilman ${ }^{2,3}$, J. M. Roberts ${ }^{2}$, W. C. Kuster ${ }^{2}$, C. Warneke ${ }^{2,3}$, I. R. Burling ${ }^{4}$, and J. de Gouw ${ }^{2,3}$ \\ ${ }^{1}$ Department of Chemistry and Biochemistry, University of Colorado, Boulder, CO 80309, USA \\ ${ }^{2}$ Chemical Sciences Division, Earth System Research Laboratory, National Oceanic and Atmospheric Administration, \\ Boulder, CO 80305, USA \\ ${ }^{3}$ Cooperative Institute for Research in Environmental Sciences, University of Colorado, Boulder, CO 80309, USA \\ ${ }^{4}$ University of Montana, Department of Chemistry, Missoula, USA
}

Received: 8 January 2010 - Published in Atmos. Meas. Tech. Discuss.: 29 January 2010

Revised: 1 June 2010 - Accepted: 7 June 2010 - Published: 16 June 2010

\begin{abstract}
We report on the development of an accurate, portable, dynamic calibration system for volatile organic compounds (VOCs). The Mobile Organic Carbon Calibration System (MOCCS) combines the production of gas-phase VOC standards using permeation or diffusion sources with quantitative total organic carbon (TOC) conversion on a palladium surface to $\mathrm{CO}_{2}$ in the presence of oxygen, and the subsequent $\mathrm{CO}_{2}$ measurement. MOCCS was validated using three different comparisons: (1) TOC of high accuracy methane standards compared well to expected concentrations (3\% relative error), (2) a gas-phase benzene standard was generated using a permeation source and measured by TOC and gas chromatography mass spectrometry (GCMS) with excellent agreement ( $<4 \%$ relative difference), and (3) total carbon measurement of 4 known gas phase mixtures were performed and compared to a calculated carbon content to agreement within the stated uncertainties of the standards. Measurements from laboratory biomass burning experiments of formic acid by negative-ion proton-transfer chemical-ionization mass spectrometry (NI-PT-CIMS) and formaldehyde by proton transfer reaction-mass spectrometry (PTR-MS), both calibrated using MOCCS, were compared to open path Fourier transform infrared spectroscopy (OPFTIR) to validate the MOCCS calibration and were found to compare well ( $R^{2}$ of 0.91 and 0.99 , respectively).
\end{abstract}

Correspondence to: P. Veres

(Patrick.veres@noaa.gov)

\section{Introduction}

Volatile organic compounds (VOCs) are emitted to the atmosphere from a variety of sources, both natural and man-made. In the atmosphere, the photo-oxidation of VOCs leads to formation of ozone and organic aerosol, which are both significant pollutants and alter radiative forcing in the Earth's climate system. Accurate measurements of ambient VOCs in the atmosphere or laboratory using analytical techniques such as gas-chromatography (Rappengluck et al., 2006) or PTR-MS (de Gouw and Warneke, 2007) rely on the accuracy of the calibration methods used. For many VOCs, but especially for "sticky" compounds that have a high affinity for metal surfaces, accurate calibration systems are not readily available. VOC standards for instrument calibration are generally produced either statically or dynamically. Static methods rely on mixtures of gases in closed containers of known volume, while dynamic processes involve mixing a continuous flow of analyte into a dilution or carrier stream. A comprehensive review of standard generation processes for VOC can be found elsewhere (Barratt, 1981; Namiesnik, 1984; Naganowska-Nowak et al., 2005)

Modern static techniques most commonly utilize mixtures of gases in treated high-pressure cylinders (Apel et al., 1998; Rappengluck et al., 2006; Apel et al., 1994). Static techniques are the preferred calibration method for many field and laboratory investigations due to the portability and robust nature of high-pressure gas cylinders. Standard mixtures are stable for many VOCs; however, wall losses and degradation become significant for highly polar and reactive compounds.

Published by Copernicus Publications on behalf of the European Geosciences Union. 
Dynamic standard generation can avoid the problem of wall losses and degradation by continuously flowing analyte into a carrier stream. This method is more suitable for polar and reactive species which would otherwise be lost to surfaces at low mixing ratios (Barratt, 1981). The two most commonly used techniques are standard generation through the use of diffusion cells (Thompson and Perry, 2009; Altshuller and Cohen, 1960; Possanzini et al., 2000; Namiesnik et al., 1981; Williams et al., 2000) and permeation sources (Okeeffe and Ortman, 1966). Diffusion sources are often used in place of permeation sources when the latter is unavailable or behavior of a substance in a permeation source is nonideal (i.e. degradation, low permeation rate, etc.) (Barratt, 1981). A combination of static and dynamic standard generation is also often used where a high mixing ratio (ppmv) static mixture is diluted dynamically. This allows for convenient portability but losses are not as significant as with very low mixing ratio static sources.

Total carbon measurement by conversion to $\mathrm{CO}_{2}$ and nondispersive infrared (NDIR) sensor analysis has long been used for analysis of a range of environmental samples ranging from natural waters to bulk collected aerosol particles. Total organic carbon (TOC) measurements of gas phase nonmethane hydrocarbons using oxidative catalysts, followed by reduction to methane, have been used in previous work (Maris et al., 2003; Roberts et al., 1998). Ambient VOC levels are frequently below the detection limits of these gas phase TOC measurement techniques, which need to account for the large concentrations of ambient $\mathrm{CO}_{2}$, methane, and carbon monoxide and make them unsuitable for ambient analyses. The TOC technique is however particularly well suited for the analysis of calibration standards where the mass loading can be user-varied to fall within a measureable range and the effects of carrier gas $\mathrm{CO}_{2}$ can be eliminated. While the technique used here is similar to TOC methods utilizing the catalytic conversion of organic carbon, we use a direct measurement of the $\mathrm{CO}_{2}$ produced in this process as a calibration measurement.

In this work we developed a mobile organic carbon calibration system (MOCCS) for the generation and absolute measurements of calibrated VOC mixtures in air that is relatively inexpensive and easy to set up. The MOCCS combines the production of standards using permeation or diffusion sources, quantitative catalytic conversion of carbon containing species to $\mathrm{CO}_{2}$, and subsequent $\mathrm{CO}_{2}$ measurement. Validation of this technique was performed in a three-part analysis: (1) two high accuracy methane standards were analyzed and compared to their known concentrations, (2) comparison of measurements by gas chromatography mass spectrometry (GC-MS) and MOCCS of a benzene standard generated using a permeation source with the system described here, and (3) several complex gravimetrically prepared VOC standards were analyzed for total carbon content.

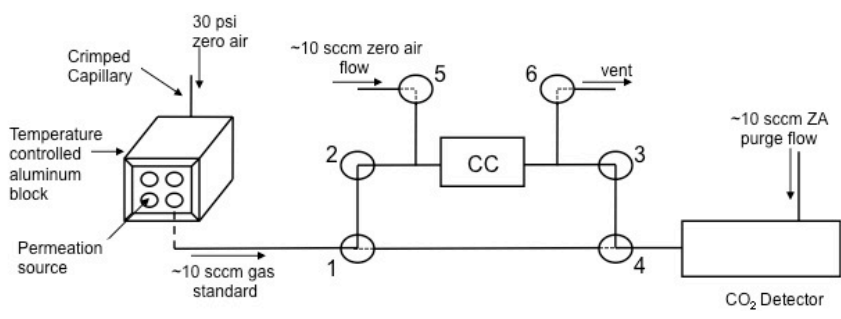

Fig. 1. A schematic diagram of the TOC calibration system. Gas standards are selectively passed over a palladium catalyst (CC). The $\mathrm{CO}_{2}$ generated via oxidation of a standard is then measured using NDIR. During a background measurement, valves 1 and 4 open to allow flow to bypass the catalyst. At this time, valves 2 and 3 are closed shut and valves 5 and 6 are opened to flush the catalyst with zero air. To make a total carbon measurement, valves 2 and 3 opened, 5 and 6 closed, and valves 1 and 4 are switched to allow the sample to flow through the catalyst with the outflow to the $\mathrm{CO}_{2}$ detector.

\section{Experimental details}

\subsection{Mobile Oxidative Carbon Calibration System (MOCCS)}

MOCCS, shown in Fig. 1, consists of 16 flow and temperature controlled permeation tube housings, a thermostated palladium catalyst at $350^{\circ} \mathrm{C}$ to readily convert VOCs to $\mathrm{CO}_{2}$, and a $\mathrm{CO}_{2}$ detector (Beckman Industrial Model 870 NDIR or LI-COR LI-6252). The entire assembly was mounted in a portable rack that includes a high-pressure zero air cylinder and an uninterruptable power supply. These features allow MOCCS to be temporarily removed from power for transport while providing continuous temperature control and flow over the permeation sources.

The housing was designed to hold 16 permeation sources at a controlled flow. Four aluminum blocks were drilled for $1 / 2^{\prime \prime}(1.28 \mathrm{~cm})$ o.d. PFA Teflon sleeves to house four permeation sources each. A temperature probe was inserted in the center of each block and the temperature regulated using individual controllers. Each permeation housing can be operated at a separate temperature with each block housing up to four permeation sources. Sections of $1 / 16^{\prime \prime}$ $(0.16 \mathrm{~cm})$ o.d. stainless steel capillary tubing $\sim 15 \mathrm{~cm}$ long were crimped until a flow of $\sim 10 \mathrm{sccm}$ was provided to each of the 16 channels at $30 \mathrm{psi}(2.07 \mathrm{bar})$. Due to slight variations in the inlet pressure, the flow is measured for each channel at the time of calibration.

A typical permeation source calibration is based on the mass loss of the permeation tube and usually requires running for several weeks under stable conditions. MOCCS measures real time emission rates of permeation sources after equilibrating within hours. As a result, any constant VOC source can be used thereby eliminating the necessity of obtaining certified permeation sources that can be quite costly. In this work, permeation sources were made in-house using 
pure compounds placed into $1 / 4^{\prime \prime}(0.64 \mathrm{~cm})$ or $1 / 8^{\prime \prime}(0.32 \mathrm{~cm})$ Teflon permeation tubes purchased from VICI Metronics and sealed with Teflon plugs with crimped stainless steel bands. Adjusting the temperature of the permeation housing can easily vary the output of the sources.

The catalyst is comprised of a $3^{\prime \prime}(3.62 \mathrm{~cm})$ length $1 / 4^{\prime \prime}$ $(0.64 \mathrm{~cm})$ o.d. stainless steel tube packed with $10 \% \mathrm{Pd}$ on Kaowool (Johnson-Matthey, Ward Hill, MA.) and capped with a small amount of glass wool, to prevent the palladium from exiting the catalyst. A thermocouple is attached to the midpoint of the stainless steel tubing and then wrapped in a single layer of insulated Nichrome wire. The finished catalyst is well insulated and placed into an aluminum box with $1 / 4^{\prime \prime}(0.64 \mathrm{~cm})$ Swagelok bulkhead unions. A 24 Volt temperature controller is used to supply power to the Nichrome wire and set the temperature to $350^{\circ} \mathrm{C}$. This catalyst design is based on that used for PTR-MS background measurements (de Gouw and Warneke, 2007). Conversion efficiencies of $\mathrm{C}_{1}-\mathrm{C}_{7}$ compounds on a $\mathrm{Pd} /$ aluminum catalyst has previously been shown to be quantitative (Roberts et al., 1998).

The flow system was designed for the sample stream to be analyzed for both background $\mathrm{CO}_{2}$ in the carrier gas and total organic carbon. A schematic of the flow system is shown in Fig. 1. The system was designed to continuously cycle between background $\mathrm{CO}_{2}$ measurement and standard calibration on a user-defined timescale. Background $\mathrm{CO}_{2}$ measurements are made by flowing the carrier gas through the permeation directly source into the $\mathrm{CO}_{2}$ analyzer bypassing the catalyst. Measuring the background in this manner accounts for any $\mathrm{CO}_{2}$ present in the carrier gas. This background is subtracted from the total organic carbon measurement. The presence of VOCs in the carrier gas must also be corrected for by subtracting a TOC measurement of the carrier gas ( $\sim 400 \mathrm{ppbv})$ prior to addition of a permeation source. The catalyst is kept under constant flow by flushing with $10 \mathrm{sccm}$ zero air when the background is being measured.

A Beckman Industrial Model 870 NDIR was used to measure the $\mathrm{CO}_{2}$ concentrations for most results presented here. Four $\mathrm{CO}_{2}$ standards in ultrapure air (Scott-Marin Inc.) ranging from $2.065( \pm 0.207)$ ppmv up to $50.1( \pm 0.5)$ ppmv were used to calibrate the NDIR. The results of the calibration are shown in Fig. 2. The precision in NDIR $\mathrm{CO}_{2}$ measurements through the calibrated concentration range was $\pm(1 \%$ of the measurement $+30 \mathrm{ppbv}$ ). The accuracy of $\mathrm{CO}_{2}$ measurements through the 2 ppmv to 50 ppmv concentration range was \pm ( $4 \%$ of the measurement +400 ppbv). Significant improvements in both precision and accuracy were made by substitution of a LI-COR LI-6252 $\mathrm{CO}_{2}$ analyzer and will be presented later in this discussion.

This TOC technique has been previously used to calibrate standards from diffusion sources for organic acids in the development of negative-ion proton-transfer chemicalionization mass spectrometry (NI-PT-CIMS) (Veres et al., 2008). The diffusion flow system used in that particular study was identical to that described in Williams et al. (2000).

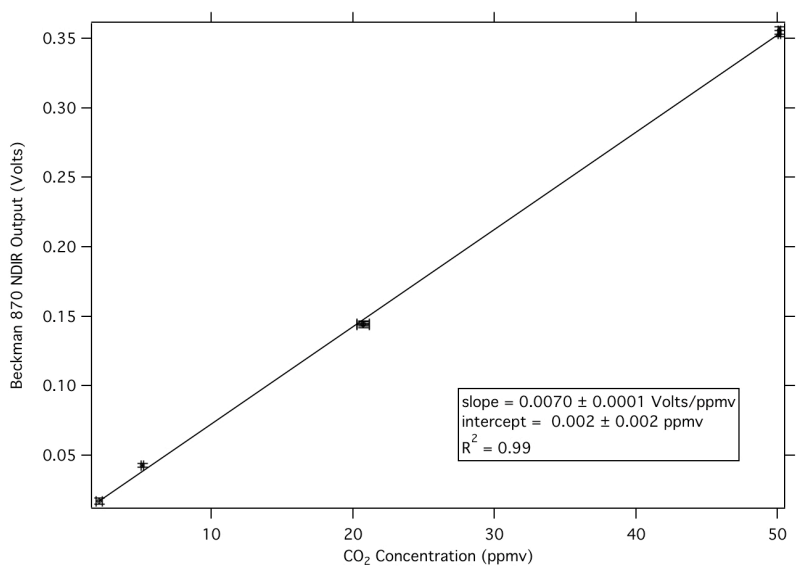

Fig. 2. Calibration of the Beckman $870 \mathrm{NDIR} \mathrm{CO}_{2}$ analyzer. Four $\mathrm{CO}_{2}$ gas standards were used: $2.065( \pm 0.207) \mathrm{ppmv}$, $5.12( \pm 0.10)$ ppmv, $20.07( \pm 0.40)$ ppmv, and $50.1( \pm 0.5)$ ppmv.

\subsection{GC-MS}

A custom built gas chromatograph with a quadrupole mass spectrometer detector (GC-MS) was used to independently verify the concentrations of two benzene standards generated and calibrated by the MOCCS. A detailed description of the GC-MS is described by Goldan et al. (2004). The output of the benzene permeation tube was first diluted in humidified nitrogen by factors of $9.78( \pm 0.11) \times 10^{-4}$ and $8.62( \pm 0.11) \times 10^{-4}$. This was done in order to avoid overloading the GC-MS, which normally operates in the pptv to ppbv range. The GC-MS collected each sample directly from the diluted sample stream before subsequent analysis. A minimum of 10 replicate samples were analyzed for each benzene concentration with an overall measurement precision of $3 \%$ or better. Benzene measured by the GC-MS was independently calibrated using more than 20 single- and multi-component VOC mixes over the lifetime of the GCMS. The GC-MS response to benzene as determined from all 20 calibration mixes has an overall measurement uncertainty of $\pm 20 \%$.

\subsection{NI-PT-CIMS}

Negative-ion proton-transfer chemical-ionization Mass Spectrometry (NI-PT-CIMS) provides gas-phase acid measurements with one-second time resolution. A detailed description of NI-PT-CIMS can be found elsewhere (Veres et al., 2008). Briefly, NI-PT-CIMS consists of (1) a ${ }^{210} \mathrm{Po}$ source to produce acetate ions $\left(\mathrm{CH}_{3} \mathrm{C}(\mathrm{O}) \mathrm{O}^{-}\right)$from acetic anhydride, (2) a flow tube reactor, in which $\mathrm{CH}_{3} \mathrm{C}(\mathrm{O}) \mathrm{O}^{-}$ undergoes proton transfer reactions with inorganic and organic acids, (3) a collisional dissociation chamber (CDC) to decluster ions, and (4) a quadrupole mass spectrometer for the detection of both reagent and product ions. 


\subsection{OP-FTIR}

The open path Fourier transform infrared (OP-FTIR) instrument included a Bruker Matrix-M IR Cube spectrometer and a thermally stable open White cell. The White cell path length was set to $58 \mathrm{~m}$. The spectral resolution was set to $0.67 \mathrm{~cm}^{-1}$ and the spectrometer acquired spectra every $1.5 \mathrm{~s}$ (four co-added spectra). A pressure transducer and two temperature sensors were located adjacent to the optical path and were logged on the instrument computer and used for spectral analysis. Mixing ratios were obtained by multicomponent fits to sections of the IR transmission spectra with a synthetic calibration non-linear least-squares method (Griffith, 1996; Yokelson et al., 2007).

\subsection{PTR-MS}

Proton transfer reaction-mass spectrometry (PTR-MS) utilizes proton-transfer reactions of $\mathrm{H}_{3} \mathrm{O}^{+}$to detect various atmospheric trace gases, usually as the $\mathrm{MH}^{+}$ion. PTRMS allows for the detection of numerous volatile organic compounds with high sensitivity (10-100 pptv) and response time (1-10s). This technique has been used extensively in aircraft, ground-based and laboratory studies. A more complete discussion of the PTR-MS system used in this study can be found elsewhere (de Gouw and Warneke, 2007).

\subsection{Gas standards}

A detailed list of the standards used in this work is shown in Table 1. VOC mix 1-4 are high-pressure gas cylinder standards prepared at NOAA ESRL/CSD laboratory using gravimetric techniques. The single component error in these laboratory-generated standards is estimated to be no greater than $20 \%$. Two high accuracy methane standards that were prepared gravimetrically with an uncertainty of $\pm 0.2 \%$ (Dlugokencky et al., 2005) were borrowed from NOAA's Global Monitoring Division (Boulder, CO) and analyzed for TOC. The stated standard concentrations of $\mathrm{CH}_{4}$ (a) and $\mathrm{CH}_{4}$ (b) were $5.75 \pm 0.11$ ppmv and $10.79 \pm 0.22$ ppmv, respectively. A laboratory-made benzene permeation source was equilibrated and calibrated by MOCCS for analysis.

\section{Validation of the MOCCS}

\subsection{Data analysis}

The results of the measurement of a benzene standard generated using the MOCCS as an example is shown in Fig 3. Interpolated background measurements are subtracted from the total organic carbon measurements to obtain a concentration for the source compound. Dividing the result by the number of carbons in the parent molecule (6) gives the original standard concentration on a molar basis, assuming a conversion ratio of $1: 1$ for the oxidation of carbon to $\mathrm{CO}_{2}$. The signal
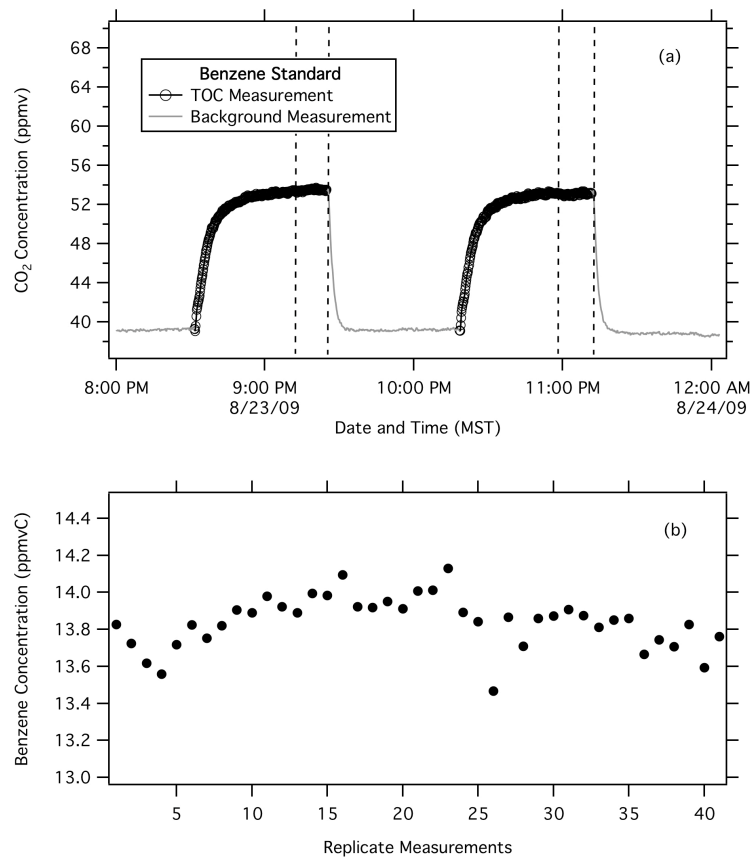

Fig. 3. $\mathrm{CO}_{2}$ measurements showing two complete cycles of background and TOC measurement of a benzene standard generated by MOCCS, Fig. 3a. The TOC measurements are shown in black with open circles and the background measurements are shown in grey. Subtracting the interpolated background and dividing the result by the number of carbon atoms in a benzene molecule (6) gives the benzene concentration from the permeation source. After the signal stabilizes, an average of the measured signal minus background is taken (shown as the data between the dashed line). Shown in Fig. 3b are replicate measurements of the benzene concentration made over the course of five days. The average concentration over this time period ( 38 cycles) was determined to be $13.8 \pm 1.0 \mathrm{ppmv}$ of carbon (ppmvC).

after the initial response time is then averaged to obtain an average standard concentration for each cycle. The inset in Fig. 3 shows the stability of the MOCCS that had a measured precision of better than $1 \%$ over 5 days. All of the TOC measured concentrations reported here are the averages of a minimum of 10 cycles. The duration of each cycle can be readily adjusted to allow for different time responses of the system to various compounds, which is dependent on their unique chemical properties (e.g. volatility, polarity, etc.).

\subsection{Methane conversion to $\mathrm{CO}_{2}$}

The results of the two comparisons for the methane standards are shown in Fig. $4 \mathrm{a}$ as $\mathrm{CH}_{4}$ (a) and $\mathrm{CH}_{4}$ (b). The TOC determined methane concentration was determined as $5.9 \pm 0.6$ ppmv for $\mathrm{CH}_{4}$ (a) and $10.8 \pm 0.8$ ppmv for $\mathrm{CH}_{4}$ (b). The relative errors in concentration between the TOC system and provided standard concentration were less than $3 \%$ in both cases and the two determinations agreed within the stated uncertainties. 
Table 1. Standard gas mixtures.

\begin{tabular}{|c|c|c|c|}
\hline Standard Name & Contents & $\begin{array}{l}\text { Concentration } \\
(\mathrm{ppmv}, \pm 20 \% \mathrm{a})\end{array}$ & $\begin{array}{l}\text { [Calculated Nominal Carbon } \\
\text { after dilution] }{ }^{\mathrm{b}} \text { (ppmv) }\end{array}$ \\
\hline \multirow[t]{7}{*}{ VOC Mix 1} & & & $9.41(4.62)$ \\
\hline & 2-methylfuran & 10.01 & \\
\hline & Methyl vinyl ketone & 7.53 & \\
\hline & Benzene & 10.53 & \\
\hline & Furfural (2-furanaldehyde) & 10.68 & \\
\hline & a-methyl styrene & 12.44 & \\
\hline & p-cymene & 10.44 & \\
\hline \multirow[t]{11}{*}{ VOC Mix 2} & & & $3.17(2.01)$ \\
\hline & Acetaldehyde & 2.01 & \\
\hline & Methanol & 1.96 & \\
\hline & Isoprene & 1.97 & \\
\hline & Acetone & 1.89 & \\
\hline & Acetonitrile & 2.01 & \\
\hline & Methacrolein & 2.09 & \\
\hline & 2-butanone & 1.92 & \\
\hline & Benzene & 1.97 & \\
\hline & b-pinene & 1.91 & \\
\hline & 1,3,5-Trimethylbenzene & 1.90 & \\
\hline \multirow[t]{8}{*}{ VOC Mix 3} & & & $10.00(5.30)$ \\
\hline & MBO & 10.73 & \\
\hline & 2,3-Butanedione & 5.82 & \\
\hline & 2-Butenal & 8.56 & \\
\hline & Toluene & 10.62 & \\
\hline & Decene & 8.69 & \\
\hline & Benzofuran & 11.01 & \\
\hline & Indene & 11.46 & \\
\hline \multirow[t]{7}{*}{ VOC Mix 4} & & & $6.19(3.03)$ \\
\hline & Acetylene & 13.41 & \\
\hline & Propene & 11.30 & \\
\hline & 1,3-Butadiene & 10.54 & \\
\hline & MTBE & 9.50 & \\
\hline & Benzene & 9.41 & \\
\hline & Benzaldehyde & 9.73 & \\
\hline \multirow[t]{2}{*}{$\mathrm{CH}_{4}$ (a) } & & & 5.75 \\
\hline & Methane & $5.75 \pm 0.11$ & \\
\hline \multirow[t]{2}{*}{$\mathrm{CH}_{4}$ (b) } & & & 10.79 \\
\hline & Methane & $10.79 \pm 0.22$ & \\
\hline
\end{tabular}

a The error in the concentration of the species listed is assumed to be $20 \%$ unless otherwise stated.

${ }^{b}$ Errors shown in parenthesis are RMS errors propagated from the assumed $20 \%$ single component error.

\subsection{Benzene conversion to $\mathrm{CO}_{2}$}

A benzene permeation source in the MOCCS was measured using both GC-MS and TOC. The results of the comparison are shown in Fig. 4b. Two permeation temperature settings were used to generate different concentrations, $7.36 \pm 0.14 \mathrm{ppmv}$ and $3.79 \pm 0.10 \mathrm{ppmv}$ as measured by TOC. The source output was diluted for analysis with GC-MS: dilution factors of $9.78( \pm 0.11) \times 10^{-4}$ and $8.62( \pm 0.11) \times 10^{-4}$ were used. GC-MS-measured benzene concentrations, after taking dilution into account, were
$7.11 \pm 1.42 \mathrm{ppmv}$ and $3.65 \pm 0.73 \mathrm{ppmv}$, respectively. The relative difference between TOC and GC-MS measurements is less than $4 \%$ for both standards measured.

\subsection{TOC of VOC standard mixtures}

VOC mixtures were diluted such that the TOC falls within the calibrated range of the Beckmann analyzer and subsequently analyzed using the MOCCS system. Results of the total carbon analysis are shown in Fig. 5 for each of the VOC mixtures available. The $\mathrm{CO}_{2}$ concentration reported is the 

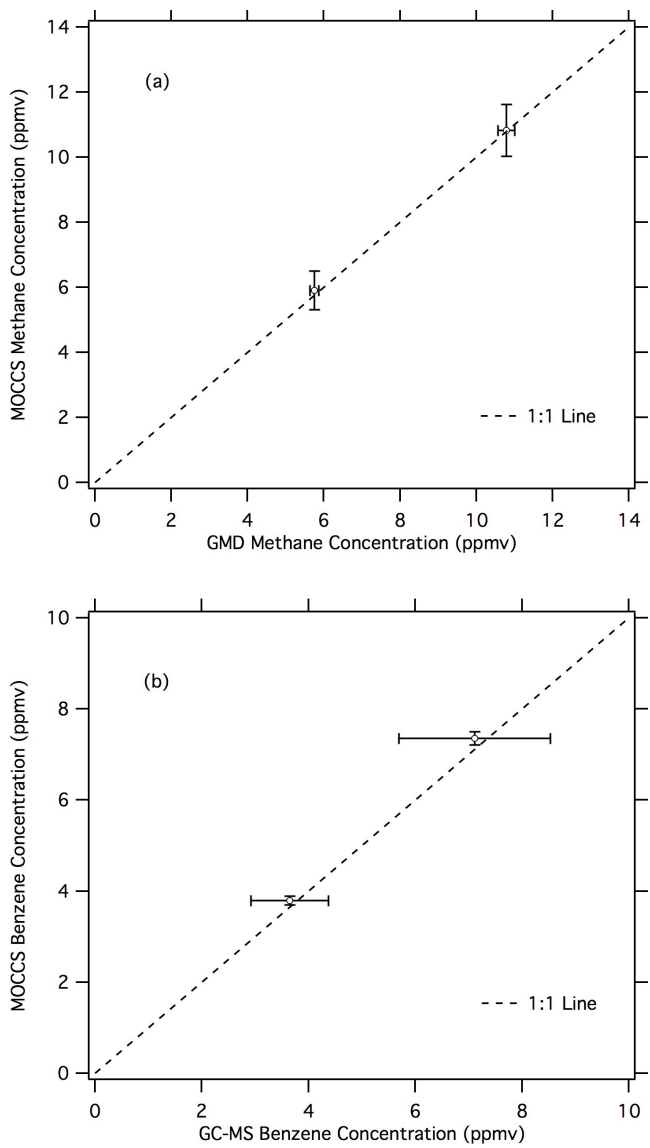

Fig. 4. Results of MOCCS determined methane concentration compared to GMD determined methane concentration of two standards, Fig. 4a. The relative difference between the two measurements is $3 \%$. The results of GC-MS/TOC measurements of two benzene standards generated using MOCCS, Fig. 4b. The relative difference between the two measurements is less than $4 \%$.

total carbon concentration of the diluted standards (striped bars). Error in the nominal carbon as derived from cylinder values for the NOAA generated standards is calculated through the propagation of the error associated with each standard component $(20 \%)$ and is listed in Table 1. TOC measured concentrations are shown in solid grey. Error $(1 \sigma)$ in the MOCCS measurements shown in Fig. 4 represent the RMS of the standard deviation from the average of multiple TOC cycles (5\%), the error associated with the calibration of the Beckman NDIR \pm ( $4 \%$ of the measurement $+400 \mathrm{ppbv}$ ), and error in the dilution flows (2\%). The agreement for all measurements is within the estimated error of the laboratory standards. The absolute error in the calculated nominal carbon concentration in the four standards analyzed as measured by MOCCS is less than $15 \%$.

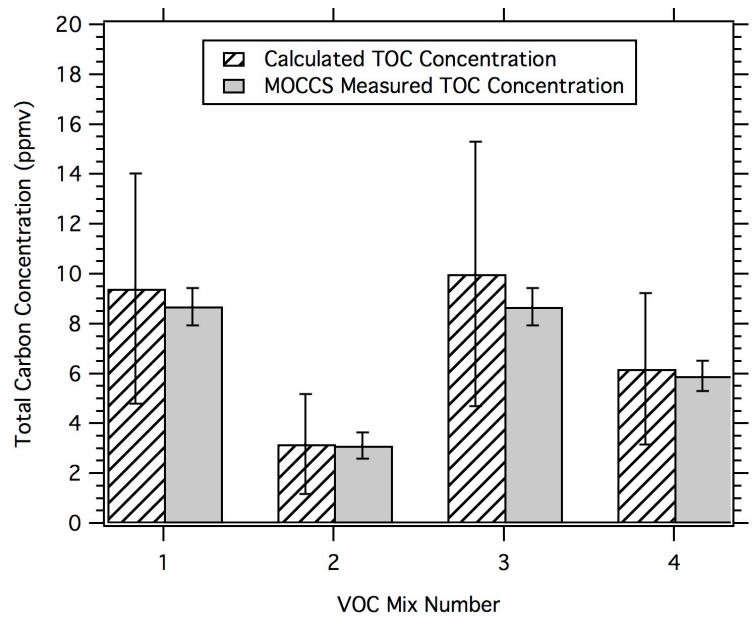

Fig. 5. The results of a total carbon analysis of 4 gas phase VOC standards. The contents of each mixture are detailed in Table 1. An uncertainty of $20 \%$ was assumed for each component in the laboratory-generated VOC standards.

\subsection{MOCCS field calibration}

MOCCS was recently used during a study preformed at the combustion facility at the US Department of Agriculture (USDA) Forest Service, Fire Sciences Laboratory (FSL) in Missoula, MT. A more in-depth discussion of this study can be found in Veres et al. (2009). Briefly, emissions of controlled laboratory biomass fires were sampled directly from a stack in which the fire emissions were completely entrained. A negative-ion proton-transfer chemical ionization mass spectrometer (NI-PT-CIMS) was calibrated for formic acid using a permeation standard that was generated and calibrated with MOCCS. A proton-transfer-reaction mass spectrometer (PTR-MS) was calibrated for formaldehyde measurements using MOCCS. Simultaneous measurements of both formic acid and formaldehyde were made using openpath Fourier transform infrared spectrometer (OP-FTIR) and were used to validate the MOCCS calibration of NI-PTCIMS and PTR-MS. Figure 6 shows a time profile for both formic acid, measured by NI-PT-CIMS and OP-FTIR, and formaldehyde, measured by PTR-MS and OP-FTIR.

The results of a comparison of NI-PT-CIMS and OP-FTIR formic acid emission measurements from a single laboratory biomass fire are shown in Fig. 6a. A scatter plot of the data shown gives a slope of an orthogonal distance regression of $0.91 \pm 0.02$ with a correlation $\left(R^{2}\right)$ of 0.91 . This agreement is well within the stated uncertainty of both instruments. Figure $6 \mathrm{~b}$ shows the results of a comparison of PTR-MS and OPFTIR formaldehyde emission measurements from the same laboratory controlled biomass fire shown in Fig. 6a. The slope is $1.06 \pm 0.02$ with a correlation $\left(R^{2}\right)$ of 0.99 from the corresponding formaldehyde scatter plot. The detection of formaldehyde by PTR-MS is humidity dependent 
Table 2. Performance of MOCCS with the Beckman Industrial Model 870 NDIR and the LI-COR LI-6252.

\begin{tabular}{lll}
\hline & Beckman 870 & LI-6252 \\
\hline Response time* $^{*}$ & $300 \mathrm{~s}$ & $90 \mathrm{~s}$ \\
TOC Detection Limit & $150 \mathrm{ppbv}$ & $5 \mathrm{ppbv}$ \\
TOC Accuracy & $\pm(4 \%$ of the measurement & $\pm(1 \%$ of the measurement \\
& $+400 \mathrm{ppbv})$ & $+80 \mathrm{ppbv})$ \\
TOC Precision & $\pm(1 \%$ of the measurement & $\pm(1 \%$ of the measurement \\
& $+30 \mathrm{ppbv})$ & $+1 \mathrm{ppbv})$ \\
Error on replicate TOC cycles & $5 \%$ & $1 \%$ \\
\hline
\end{tabular}

* Response times are listed for a formic acid permeation source.
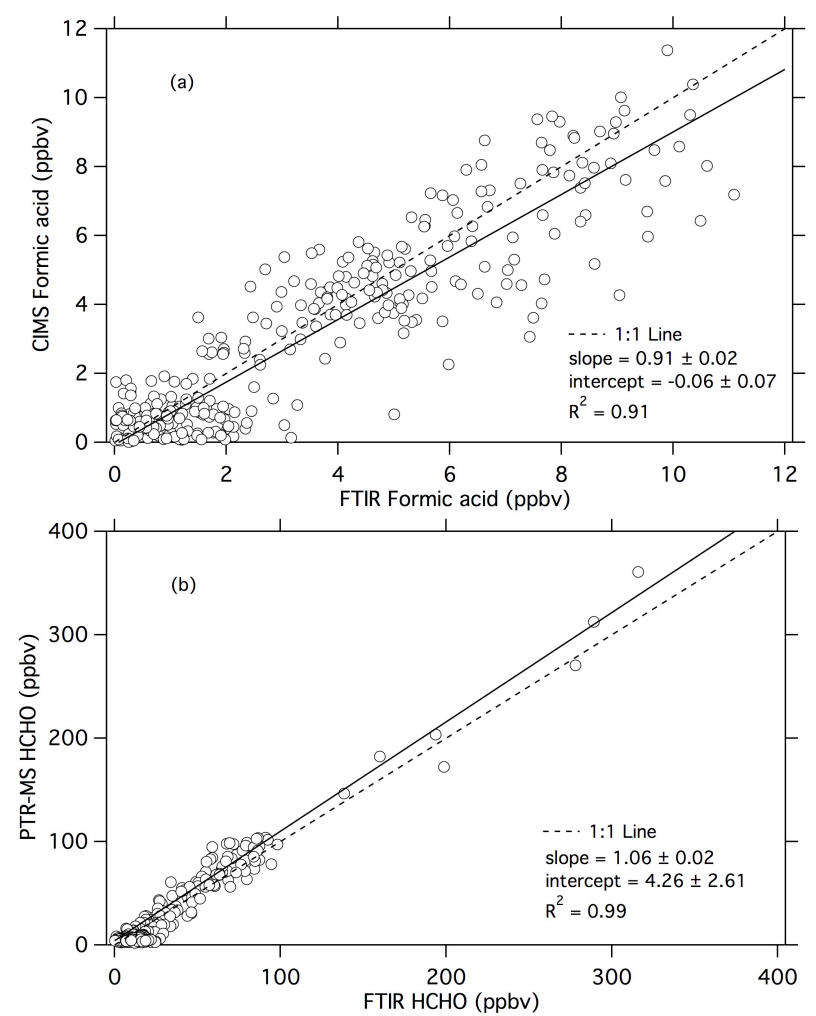

Fig. 6. A comparison of NI-PT-CIMS formic acid and PTR-MS formaldehyde measurements to simultaneous measurement of OPFTIR formic acid and formaldehyde. NI-PT-CIMS was calibrated using a formic acid permeation source that was standardized using MOCCS. PTR-MS was calibrated for formaldehyde measurement with a permeation source that was standardized using MOCCS.

(Hansel et al., 1997); however, the humidity dependence is ignored here, the relative humidity during calibration and fire measurements were similar for this particular experiment. A study of the sensitivity of PTR-MS for formaldehyde as a function of humidity is beyond the scope of the present work. The agreement between PTR-MS and OP-FTIR in this comparison is well within the estimated uncertainty of both instruments. The agreement between these two sets of inde-

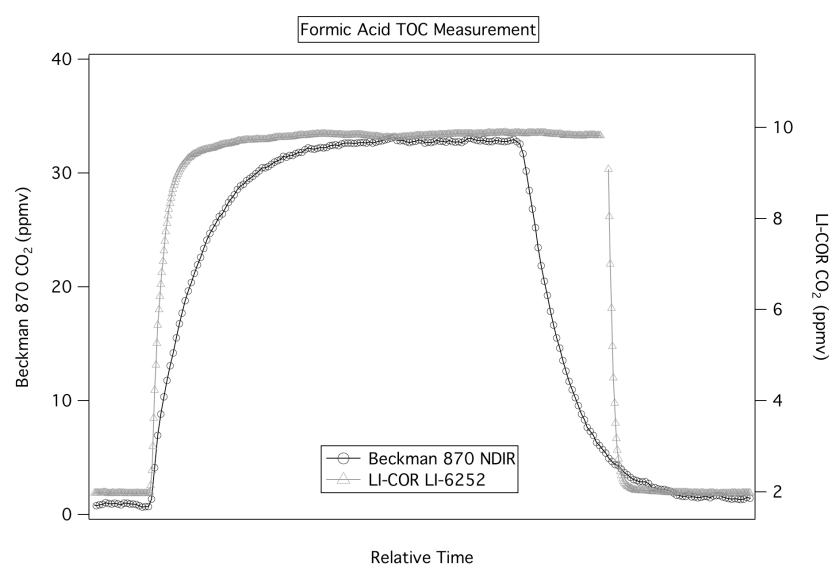

Fig. 7. Formic acid measurement comparison using MOCCS with the Beckman model 870 NDIR $\mathrm{CO}_{2}$ analyzer and the LI-COR LI$6252 \mathrm{CO}_{2}$ analyzer. The TOC system was set to a 1-h cycle between $\mathrm{CO}_{2}$ catalysis measurements and background measurement. Significant improvements in both $\mathrm{CO}_{2}$ detection limit and instrument response times are achieved with the LI-COR LI-6252 analyzer. It is important to note that the two $\mathrm{CO}_{2}$ measurements are not of the same formic acid standard, which explains the difference in left and right axes.

pendently calibrated measurements validates the use of the MOCCS for VOC standard production and calibration.

\subsection{Comparison of $\mathrm{CO}_{2}$ analyzers}

A recent improvement to the MOCCS was the replacement of the Beckman model 870 NDIR $\mathrm{CO}_{2}$ analyzer with a LICOR LI-6252 $\mathrm{CO}_{2}$ analyzer. The LI-6252 system utilizes a $4.26 \mu \mathrm{m}\left(2347.4 \mathrm{~cm}^{-1}\right)$ absorption band for $\mathrm{CO}_{2}$. Various compounds, such as isocyanates and alkynes, present a potential interference at this wavelength (Lide, 2005). Additional work is necessary to determine a proper zeroing technique when measuring classes of compounds that present interferences. Within the context of this particular study the potential for absorption interferences is negligible. Table 2 summarizes the results of a comparison of the two $\mathrm{CO}_{2}$ 
analyzers. Significant improvements in the instrument response times and detection limits are observed with the LICOR analyzer. Figure 7 shows the results of a comparison in formic acid response times and detection limits as defined by one complete MOCCS cycle. The formic acid response time, defined as the time required for a calibration signal to decay to $10 \%$ of the initial value when the source is removed, was approximately $90 \mathrm{~s}$ for the LI-COR compared to over $300 \mathrm{~s}$ for the Beckman analyzer. The detection limit for the compounds investigated in this study was determined from a signal-to-noise ratio of 2 as twice the standard deviation in the background. The LI-COR detection limit of 5 ppbv was significantly lower than that of the Beckman analyzer, $150 \mathrm{ppbv}$. The precision in LI-COR $\mathrm{CO}_{2}$ measurements through the calibrated concentration range is $\pm(1 \%$ of the measurement $+1 \mathrm{ppbv}$ ). The accuracy of LI-COR $\mathrm{CO}_{2}$ measurements through the $2 \mathrm{ppmv}$ to $50 \mathrm{ppmv}$ concentration range is \pm ( $1 \%$ of the measurement $+80 \mathrm{ppbv})$. In addition to improvements in precision, accuracy and detection limit, the overall error from the average of multiple TOC cycles is also reduced from $5 \%$ of the measurement to $1 \%$ when using the LI-COR analyzer. These improvements from use of the LI-COR analyzer compared to the Beckman NDIR analyzer are significant and show that the accuracy of this technique is highly dependent on the type of $\mathrm{CO}_{2}$ analyzer used.

\section{Conclusions}

A portable system for the dynamic production and calibration of gas phase VOCs has been developed. We use a combination of catalytic reduction of VOCs to $\mathrm{CO}_{2}$ and the subsequent measurement of the $\mathrm{CO}_{2}$ produced by an NDIR analyzer to standardize calibration sources. We have validated the TOC measurement technique through total carbon analysis of two high accuracy methane standards showing excellent agreement with 3\% absolute error. MOCCS was validated further by the production and subsequent calibration of a benzene standard by GC-MS and TOC with excellent agreement $(<4 \%$ relative difference). Four laboratory prepared mixed VOC gas-phase standards were analyzed for TOC and shown to be accurate to within $15 \%$. The MOCCS system is relatively inexpensive to develop in laboratory. It allows for dynamic generation and calibration of pure compounds, such as acids, which are not well suited for other commonly used standard generation processes. While we have shown this technique to be effective for pure hydrocarbons and simple oxy-hydrocarbons, studies of VOCs containing heteroatoms, such as nitrogen, must be performed to validate the efficacy of this method for these compounds. MOCCS is also somewhat limited in its applicability as Sand $\mathrm{Cl}$ - containing compounds are known to have the potential of deactivating such oxidation catalysts and as such may not be amenable to this technique. MOCCS is particularly well suited for field deployment, as it is completely mobile.
This technique represents a novel advancement in gas phase standard production and calibration for both VOCs and potentially SVOCs.

Acknowledgements. The authors would like to thank Edward Dlugokencky for supplying the GMD methane standards used. We also want to thank Robert J. Yokelson for his role in the SMURFS 2009 study. This work was supported by the NOAA's Health of the Atmosphere Program and NOAA's Climate Goal, NSF Grant \# ATM 1542457, the CIRES Innovative Research Program, and DOD SERDP Grant Nos. SI-1648 and SI-1649.

Edited by: D. Heard

\section{References}

Altshuller, A. P. and Cohen, I. R.: Application of diffusion cells to the production of known concentrations of gaseous hydrocarbons, Anal. Chem., 32, 802-810, 1960.

Apel, E. C., Calvert, J. G., and Fehsenfeld, F. C.: The nonmethane hydrocarbon intercomparison experiment (nomhice) - task 1 and task 2, J. Geophys. Res.-Atmos., 99, 16651-16664, 1994.

Apel, E. C., Calvert, J. G., Greenberg, J. P., Riemer, D., Zika, R., Kleindienst, T. E., Lonneman, W. A., Fung, K., and Fujita, E.: Generation and validation of oxygenated volatile organic carbon standards for the 1995 southern oxidants study nashville intensive, J. Geophys. Res.-Atmos., 103, 22281-22294, 1998.

Barratt, R. S.: The preparation of standard gas-mixtures - a review, Analyst, 106, 817-849, 1981.

de Gouw, J. A. and Warneke, C.: Measurements of volatile organic compounds in the earth's atmosphere using proton-transferreaction mass spectrometry, Mass Spectrom. Rev., 26, 223-257, 2007.

Dlugokencky, E. J., Myers, R. C., Lang, P. M., Masarie, K. A., Crotwell, A. M., Thoning, K. W., Hall, B. D., Elkins, J. W., and Steele, L. P.: Conversion of noaa atmospheric dry air $\mathrm{CH}_{4}$ mole fractions to a gravimetrically prepared standard scale, J. Geophys. Res.-Atmos., 110, D18306, doi:10.1029/2005jd006035, 2005.

Griffith, D. W. T.: Synthetic calibration and quantitative analysis of gas-phase ft-ir spectra, Appl. Spectrosc., 50, 59-70, 1996.

Hansel, A., Singer, W., Wisthaler, A., Schwarzmann, M., and Lindinger, W.: Energy dependencies of the proton transfer reactions $\mathrm{H}_{3} \mathrm{O}^{+}+\mathrm{CH}_{2} \mathrm{O} \nRightarrow \mathrm{CH}_{2} \mathrm{OH}^{+}+\mathrm{H}_{2} \mathrm{O}$, Int. J. Mass Spectrom., 167, 697-703, 1997.

Lide, D. R.: CRC Handbook of Chemistry and Physics, CRC Press, Boca Raton, FL, 2005.

Maris, C., Chung, M. Y., Lueb, R., Krischke, U., Meller, R., Fox, M. J., and Paulson, S. E.: Development of instrumentation for simultaneous analysis of total non-methane organic carbon and volatile organic compounds in ambient air, ISI:000185829200010, S149-S158, 2003.

Naganowska-Nowak, A., Konieczka, P., Przyjazny, A., and Namiesnik, J.: Development of techniques of generation of gaseous standard mixtures, Crit. Rev. Anal. Chem., 35, 31-55, doi:10.1080/10408340590947916, 2005.

Namiesnik, J., Torres, L., Kozlowski, E., and Mathieu, J.: Evaluation of the suitability of selected porous polymers for precon- 
centation of volatile organic-compounds, J. Chromatogr., 208, 239-252, 1981.

Namiesnik, J.: Generation of standard gaseous-mixtures, J. Chromatogr., 300, 79-108, 1984.

Okeeffe, A. E. and Ortman, G. C.: Primary standards for trace gas analysis, Anal. Chem., 38, 760-763, 1966.

Possanzini, M., Di Palo, V., Brancaleoni, E., Frattoni, M., and Ciccioli, P.: Dynamic system for the calibration of semi-volatile carbonyl compounds in air, J. Chromatogr. A, 883, 171-183, 2000.

Rappengluck, B., Apel, E., Bauerfeind, M., Bottenheim, J., Brickell, P., Cavolka, P., Cech, J., Gatti, L., Hakola, H., Honzak, J., Junek, R., Martin, D., Noone, C., Plass-Dulmer, C., Travers, D., and Wang, D.: The first voc intercomparison exercise within the global atmosphere watch (gaw), Atmos. Environ., 40, 75087527, doi:10.1016/j.atmosenv.2006.07.016, 2006.

Roberts, J. M., Bertman, S. B., Jobson, T., Niki, H., and Tanner, R.: Measurement of total nonmethane organic carbon $\left(\mathrm{C}_{\mathrm{y}}\right)$ : development and application at chebogue point, nova scotia, during the 1993 north atlantic regional experiment campaign, J. Geophys. Res.-Atmos., 103, 13581-13592, 1998.

Thompson, J. M. and Perry, D. B.: A new system of refillable and uniquely identifiable diffusion tubes for dynamically generating voc and svoc standard atmospheres at PPM and PPB concentrations for calibration of field and laboratory measurements, J. Environ. Monitor., 11, 1543-1544, doi:10.1039/b901954e, 2009.
Veres, P., Roberts, J. M., Warneke, C., Welsh-Bon, D., Zahniser, M., Herndon, S., Fall, R., and de Gouw, J.: Development of negativeion proton-transfer chemical-ionization mass spectrometry (NIPT-CIMS) for the measurement of gas-phase organic acids in the atmosphere, Int. J. Mass Spectrom., 274, 48-55, 2008.

Veres, P., Roberts, J. M., Burling, I. R., Warneke, C., Gouw, J. d., and Yokelson, R.: Measurement of gas-phase inorganic and organic acids from biomass fires by negatiove-ion proton-transfer chemical-ionization mass spectrometry (NI-PT-CIMS), JGR Atmospheres, in review, 2009.

Williams, J., Roberts, J. M., Bertman, S. B., Stroud, C. A., Fehsenfeld, F. C., Baumann, K., Buhr, M. P., Knapp, K., Murphy, P. C., Nowick, M., and Williams, E. J.: A method for the airborne measurement of PAN, PPN, and MPAN, J. Geophys. Res.-Atmos., 105, 28943-28960, 2000.

Yokelson, R. J., Karl, T., Artaxo, P., Blake, D. R., Christian, T. J., Griffith, D. W. T., Guenther, A., and Hao, W. M.: The Tropical Forest and Fire Emissions Experiment: overview and airborne fire emission factor measurements, Atmos. Chem. Phys., 7, 5175-5196, doi:10.5194/acp-7-5175-2007, 2007. 